Auf der Altonaer Sternivarte, vom Herausgeber.

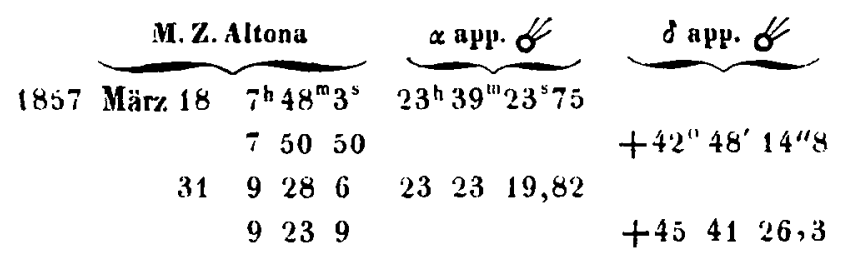

Scheinbare Örter der Vergleichsterne

März $1823^{\text {h } 39^{m} 43^{\prime \prime} 94+42^{\prime \prime} 53^{\prime} 3^{\prime \prime} 9}$

$23403,78+42,4557,5\}$

B. $\% .382$

Der Comet wurde mit beiden Sternen gleich oft in Rectascension und Declination verglichen.

März $312^{\text {h }} 21^{\mathrm{m}} 36^{\prime} 79+45^{\prime \prime} 45^{\prime} 52^{\prime \prime} 4 \quad \operatorname{\Lambda rg} . \%$.

Beobachtung des Brorsen'schen Cometen auf der Altonaer Sternwarte, vom Herausgeber.

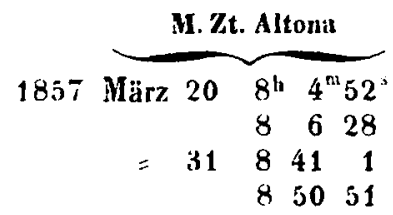

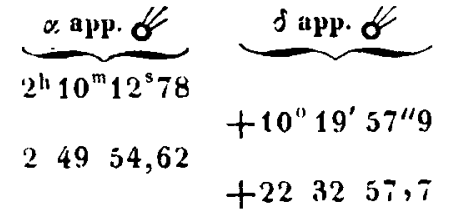

Die letzte Beobachtung ist etwas unsicher. weil sic durch Wolken angestellt wurde.

Scheinbare Örter der Vergleichsterue

März $202^{\mathrm{h}} 15^{\mathrm{m}} 33^{\mathrm{s}} 83+10^{\circ} 11^{\prime} 2^{\prime \prime} 8$ nach Bessel u. Lal. $3125510,81+222954,7$ B.Z. 27.

\title{
Wieder-Aufsuchung der Daphne.
}

Durch die so knrze Sichtbarkeit der Daphne bei ihrer ersten Erscheinung und die daraus folgende grosse Unsicherheit der Daphne-Rechnungen haben sich die Unterzcichneten veranlasst gesehen, hei der bevorstehenden Daphne-Opposition deren Aufsuchung durch folgende Theilung der Arheit za versuchen, wobei noch weitere Theilnehmer recht sehr willkommen sein werden, indem es der Witterung wegen weckmässigg erscheint, hora 22 und hora 23 doppelt zu hesetzen.

1) Zwischen $0^{\text {h }} 0^{\text {"I }}$ und $1^{\text {ll }} 0^{\text {m }}$ Rectascension wird im August, September und Octoher 1857 mit dem 6 -fïssigen Fernrohr auf der Bilker Sternwarte müglichst oft nach Daphoe gesucht werden.

Bilk 1857 Mïrz 23.

R. Luther.

2) Zwischen $23^{\text {ho }} 0^{\text {th }}$ und $23^{\text {h }} 30^{\text {th }}$ Ale wird in den obigen Monaten mit cinem $43^{\text {"It }}$ Oeffnung hahenden Cometensucher, sowic atuch möglichst oft mit dem 14 -füssigen Refractor hier nach der Daphne gesucht werden.

Berlin 1857 April ?.

C. Bruhns.

3) Je this savoir at ces Messieurs, que je ferai mon possible, pour chercher cette planète entre les limites d'AR $23^{\mathrm{h}} 30^{\mathrm{m}}$ ct $24^{\mathrm{h}} 0^{\mathrm{m}}$ en temps et lieux convenables.

Paris 1857 Avrib8.

C'kucornac.

4) Zwischen $22^{h}$ und $23^{h}$ AR so wie zwischen $23^{h} 30^{\mathrm{m}}$ und 24" AR werde ich in obengenannten Monaten suchen, mit einem Fernrohre von 4 Zoll Oefluung den Planeten wieder aufzufinden.

Paris 1857 April 8.

II. Goldschmidt.

Aul der hiesigen Stermwarte wird llerr Pape, so weit es die übrigen Arheiten erlauben, zur Aufsuchung des Planeten mit einem Ferurohr von $3 \frac{1}{2}$ Zoll Oeffumngr dic Gegend zwischen $22^{\mathrm{h}} 30^{\mathrm{m}}$ u. $23^{\mathrm{h}}$ durchmustern. Es wäre wïnschenswerth wenn sich auf andern Stermvarten einige Beobachter an dieser Aufsuchung lietheiligten: jedenfalls ist, wie auch Herr Dr. Luther lemerkt, eine von zwei Beobachtern gleichzeitig ausgeführte Durchmusterumg der Stunden 22 u. 23 sehr awecknässig. Ich füge noch hinzu dass IIr. Pape in der Kürze eine Ephemeride mittheilen wird, durch welche dic Grenzen, innerhalb deren man zu suchen hat. näher bestimmt werdeo.

Altona 1857 April 11.

l'.

Neue Elemente der Daphue

von Herru Prof. Valz, Director der Sternwarte in Harseille, mitgetheilt von Herrn Dr. R. Lutleer.

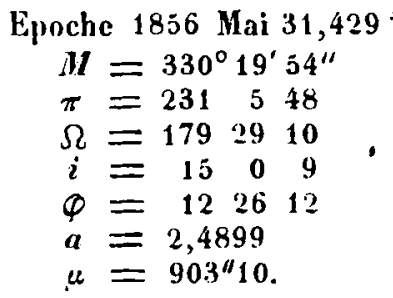

¥) Wahrscheinlich unittlere Marzeiller Zeit. 